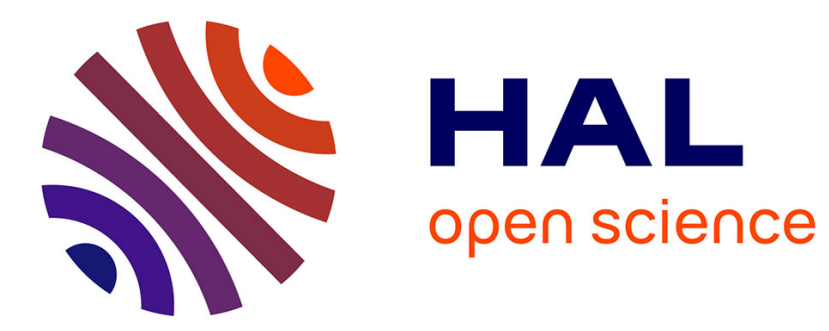

\title{
Condition monitoring and prediction of solution quality during a copper electroplating process
}

Gerardo Emanuel Granados, Loïc Lacroix, Kamal Medjaher

\section{To cite this version:}

Gerardo Emanuel Granados, Loïc Lacroix, Kamal Medjaher. Condition monitoring and prediction of solution quality during a copper electroplating process. Journal of Intelligent Manufacturing, 2018, pp.1-16. 10.1007/s10845-018-1445-4 . hal-02111876

\section{HAL Id: hal-02111876 \\ https://hal.science/hal-02111876}

Submitted on 26 Apr 2019

HAL is a multi-disciplinary open access archive for the deposit and dissemination of scientific research documents, whether they are published or not. The documents may come from teaching and research institutions in France or abroad, or from public or private research centers.
L'archive ouverte pluridisciplinaire HAL, est destinée au dépôt et à la diffusion de documents scientifiques de niveau recherche, publiés ou non, émanant des établissements d'enseignement et de recherche français ou étrangers, des laboratoires publics ou privés. 


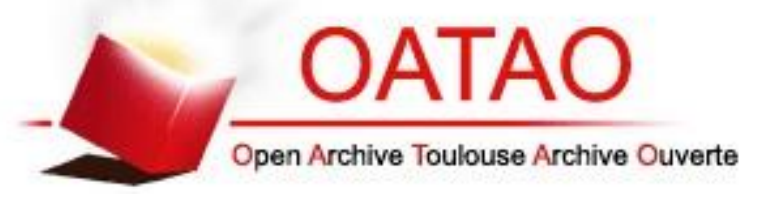

\section{Open Archive Toulouse Archive Ouverte}

OATAO is an open access repository that collects the work of Toulouse researchers and makes it freely available over the web where possible

This is an author's version published in: http://oatao.univ-toulouse.fr/21988

\section{To cite this version:}

Granados, Gerardo Emanuel and Lacroix, Loic Kamal $\fallingdotseq$ Condition monitoring and prediction of solution quality during a copper electroplating process. (2018) Journal of Intelligent Manufacturing. 1-16. ISSN 0956-5515

Any correspondence concerning this service should be sent to the repository administrator: tech-oatao@listes-diff.inp-toulouse.fr 


\title{
Condition monitoring and prediction of solution quality during a copper electroplating process
}

\author{
Gerardo Emanuel Granados $^{1} \cdot$ Loïc Lacroix $^{1} \cdot$ Kamal Medjaher $^{1}$ (D)
}

\begin{abstract}
This paper presents a method for the monitoring and prediction of the electrolyte quality during the process of copper electroplating. This is important in industry, as any deviation in the solution quality leads to a deterioration of the quality of the processed products. The aim of the study is to identify some physical parameters that are representative of the quality variation during the deposition process. These parameters are then tracked online to continuously assess the solution quality and predict its remaining useful life. To do this, the process behavior is first characterized to derive a nominal model and to identify the physical parameters that can be used to describe the aging variation in the electrolyte quality. The aging model is then explored to assess the current level of the solution quality and to predict its remaining useful life. The proposed method is verified using real data acquired from a specifically designed test bench. The obtained results reveal the efficiency of the method.
\end{abstract}

Keywords Condition monitoring · Fault prognostics · Prognostics and health management (PHM) · Remaining useful life · Copper electroplating process

\section{Introduction}

Electrochemical processes have been studied for a long time since they are applied in several industries. Among them, electroplating has played an important role in the material development and surface treatment industries. Electroplating as a surface treatment method facilitates the provision of functional properties such as corrosion resistance, changed electrical properties, or weldability, to bulk materials using coatings. The application fields of this process include personal electronic devices, hard disks, and mechanical parts. For example, in the aeronautics industry, thin multilayer platings of zinc, copper, nickel, and gold are used. In this case, the copper facilitates the absorption of the internal forces produced by the differences in the thermal coefficients. Moreover, copper plating is usually used as a preparatory layer to ensure the adhesion of following layers. Copper deposition

Kamal Medjaher

kamal.medjaher@enit.fr

Gerardo Emanuel Granados

geragranados@gmail.com

1 Production Engineering Laboratory (LGP), INP-ENIT, 65000 Tarbes, France is a technology undergoing a contemporary resurgence due to its application to integrated circuits (IC) and microfabrication in the microelectromechanical system industry (Tsai 2014; Poon et al. 2000; Ming et al. 2010; Vaezi et al. 2013).

Most of the current works in the field of electroplating are aimed at improving the microstructure and properties of the deposit by changing the initial properties of the solution and the electrochemical parameters (Paunovic and Schlesinger 2006) in accordance with nominal models. Recent studies seek a better understanding of the processes involved during plating in a solution (Yu et al. 2015). Some works aim to describe aspects of the aging of chemical solutions, changing the research focus not only to the resulting plating, but also to the solution quality (Gabrielli et al. 2006, 2004, 2008). For this purpose, and in order to guarantee acceptable solution quality, it is necessary to continuously monitor the electroplating process to detect potential drifts, identify the causes, predict the solution quality variation, and take appropriate decisions accordingly. This can be achieved by implementing Prognostics and Health Management (PHM) approaches. PHM aims at developing tools, methods, and algorithms to ensure the monitoring of system conditions, fault detection, fault diagnostics, fault prognostics, and decision support. In this field, several works are reported in the literature 
(Gouriveau et al. 2016; Mosallam et al. 2013, 2016; Ragab et al. 2016a, b; Sikorskaa et al. 2011; Vogl et al. 2016). However, the majority of these works concern physical systems (rotating machines, wind turbines, batteries, cracks caused by fatigue, etc.) and only a few of the them focus on electrochemical processes (Imai and Kitabata 2009; Imai et al. 2009; Jaworski et al. 2011, 2013). This paper aims to fill this gap by proposing a method that uses the PHM paradigm to monitor the quality of the solution in an electroplating process, detect potential drifts, and predict its Remaining Useful Life (RUL). In this case, the RUL corresponds to the time interval during which the solution properties remain acceptable to accomplish the electrodeposition, without deterioration or degradation in the final product.

PHM works can be grouped into three main approaches: model-based, data-driven, and hybrid approaches. The model-based approach requires a thorough physical understanding of the system (or process) to derive analytical models that closely describe its dynamic behavior. The datadriven approach is based on the utilization of the monitoring data provided by the sensors to extract relevant features and build health indicators that are then exploited to track the health state of the system and predict its RUL. Finally, the hybrid approach merges both previous approaches to take advantage of their respective benefits. Although the model-based approach gives more precise results than the data-driven approach, its implementation is difficult in practice due to the complexity of the systems and the difficulty involved in obtaining precise and exploitable physical models.

This paper deals with condition monitoring and RUL prediction in an electroplating process. The proposed method combines electrodeposition expertise with experimental data obtained from a test bench specifically designed and realized for this work. The aim is to monitor and track the parameters which correlate with the solution quality variation and the degradation during the electroplating process. These parameters are defined from the nominal and aging models of the process.

The first analytical aging models of electrodeposition were proposed around 1899 (Paunovic and Schlesinger 2006), based on Butler-Volmer kinetics, Faraday's law, and Tafel's law. The reported models were used later in general processes, and in particular those that are of interest for this work. As far as the authors can determine, the aging process seems to be a new purpose field with recent progress in models for electrolytic cells, and with new approaches to their study such as frequency domain characterization (Yu et al. 2015; Macdonald et al. 1998; Gabrielli et al. 2007). The IC industry has led a few studies about solution aging produced by organic components. Gabrielli et al. 2004, 2006, 2008 proposed different models to calculate the aging process, including some parameters that would quantitatively char- acterize the aging of those processes. Those aging models can be combined with the nominal model presented in Piratoba Morales et al. (2010). For the present work, constant values and known behaviors of the process were taken from Schuldiner and Rosen (1972) and Takahashi (2000) in order to present an aging model strongly supported by mathematical models. Beside the electrochemical process, the aging process has been taken into consideration in the recent literature due to its complexity and criticality. The impedance studies are considered relevant to future work but are not within the scope of the current work.

This paper presents a method that combines physicochemical modeling and some steps of the PHM paradigm to define and monitor various aging parameters relevant to solution quality variation during an electroplating process. The proposed method, merging both PHM and chemistry, creates a new tool for tracking physicochemical process aging.

The paper is organized as follows. After the introduction, "Proposed method" section presents the general overview of the proposed method and describes its main steps. Section "Application and results" presents the application of the method to real data acquired from an experimental test bench, and discusses the obtained results. Finally, Conclusions and future work section concludes the paper.

\section{Proposed method}

The method presented in this paper deals with monitoring and prediction of the solution quality of an electroplating process. Indeed, knowing the solution quality at any particular moment in time is important because any deterioration of the solution will result in a drift in the quality of the final processed product. For this purpose, the authors propose to combine both electrochemical knowledge and expertise, and PHM. The main steps of the method are presented in Fig. 1. First, the electrochemical process is studied and analyzed to understand both its nominal and aging behaviors. This study allows the identification of the physical parameters that are worthy to monitor during the realization of the process, and also enables the design of the experimental test bench that can be used to verify and validate the method. The subsections in the following process diagram outline the steps and their relationship to one another (Fig. 1).

\section{Physicochemical process}

The electrochemical process consists of the deposition of copper on metal. It involves the adhesion of copper dissolved in a copper sulfate bath with the help of $\mathrm{H}_{2} \mathrm{SO}_{4}$ (sulfuric acid) to dissolve sulfate and obtain $\mathrm{Cu}^{2+}$. The $\mathrm{SO}_{4}{ }^{2-}$ enables the production of a ductile copper coating. 


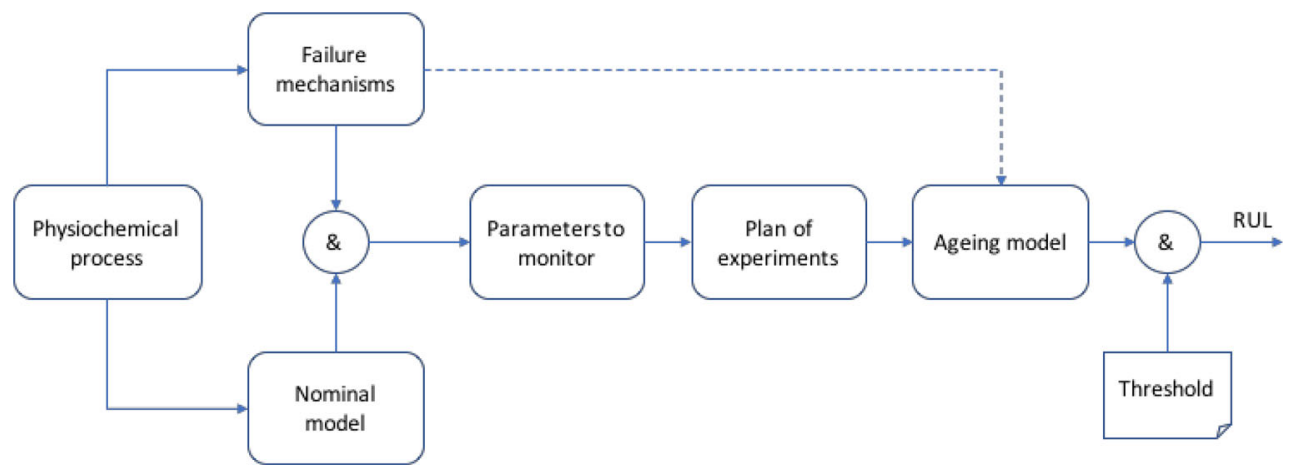

Fig. 1 Main steps of the proposed method

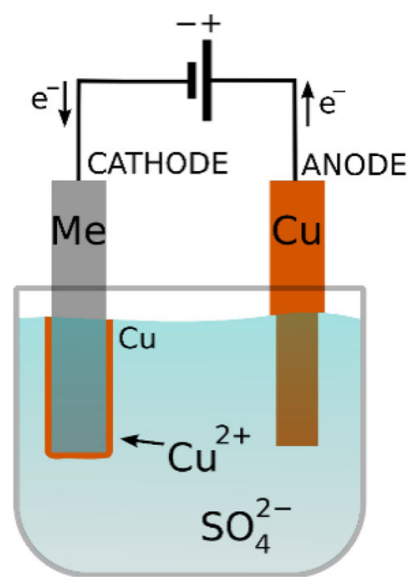

\section{Nominal model}

When an electrode is part of an electrochemical cell through which a current is flowing, its potential will differ from the equilibrium potential (Eq. 1):

$\eta=\Delta \phi(i)-\Delta \phi_{e q}$

where $\Delta \phi(i)$ is the potential resulting from the external current flow, and $\Delta \phi_{e q}$ is the equilibrium potential in the absence of external current.

The overpotential $\eta$ is composed of partial potential reactions: charge transfer, diffusion, chemical reaction, and crystallization. In this case, charge transfer will be considered the slowest reaction and will therefore determine the overall reaction rate.

Given the above consideration, it is possible to demon-

Table 1 Process parameters

\begin{tabular}{ll}
\hline $\mathrm{CuSO}_{4}, 5 \mathrm{H}_{2} \mathrm{O}$ concentration & $250 \mathrm{~g} / \mathrm{L}$ \\
$\mathrm{H}_{2} \mathrm{SO}_{4}$ concentration & $75 \mathrm{~g} / \mathrm{L}$ \\
Temperature & Controlled \\
Cathodic current density & $1-10 \mathrm{~A} / \mathrm{dm}^{2}$ (galvanostatic) \\
Agitation & Mechanical \\
Anodes & Inert metal \\
Faraday efficiency $\left(\mathrm{F}_{\mathrm{e}}\right)$ & $0.95-1$ \\
$\mathrm{pH}$ & Lower than 3 \\
\hline
\end{tabular}

The nominal process is illustrated by Fig. 2 and the corresponding parameters are listed in Table 1.

Note that surface preparation is a key step in the coating processes to obtain the best conditions for the electrochemical reactions and optimal and reproducible deposits. For example, aluminum substrates need specific scouring to eliminate the oxide layer. To avoid any artefacts due to the surface preparation, the authors have chosen copper as a substrate compatible with the study of only physicochemical coating process parameters. strate the Butler-Volmer equation (Paunovic and Schlesinger 2006) (Fig. 3) that gives the relationship between current density and charge transfer potential in terms of two parameters (Eq. 2):

$i=i_{0}\left[e^{\frac{(1-\alpha) n F}{R T} \eta}-e^{-\frac{\alpha n F}{R T} \eta}\right]$

where $i_{0}$ is the equilibrium current density, $\alpha$ is the transfer coefficient (its value is between 0 and 1 ), $n$ is the number of electrons transferred, $F$ is the Faraday constant, $R$ is the perfect gas constant, and $T$ is the temperature in Kelvin.

Two approximations of Eq. 2 can be used in the case of low overpotential (less than $10 \mathrm{mV}$ ) and high overpotential. The low-overpotential equation takes the form $i(\eta)=a e^{b \eta}$, and the high-overpotential equation takes the form of a linear function, $\eta(i)=a \log i$.

The equilibrium potential in Eq. 1 is determined by the Nernst equation:

$\Delta \phi_{e q}=\Delta \phi^{0}+\frac{R T}{z F} \ln \frac{a_{O x}}{a_{\text {Red }}}$ 


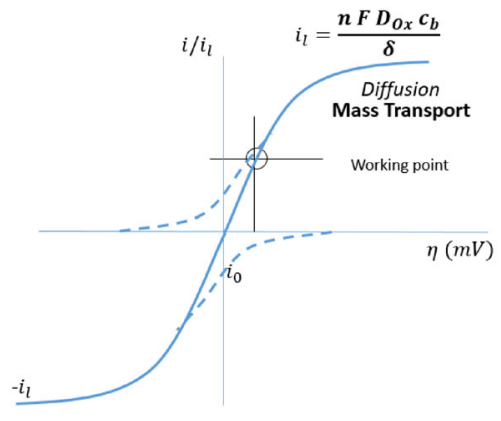

$n$ : number of electrons transferred across the electrode-

electrolyte interfaces in the reaction of one molecule of Ox.

F: Faraday constant (96500 C)

$D_{o x}$ : diffusion coefficient of the oxidized species

$C_{b}$ : concentration

Fig. 3 Variation of partial redox current densities (dashed lines) and net current density (solid line) versus overpotential (Paunovic and Schlesinger 2006)

where $a_{O x}$ and $a_{R e d}$ are the chemical activity of the oxidized and the reduced species respectively (equal to the concentration of the oxidized species, and to 1 for the metal).

The following equation describes the relationship between the exchange current and the concentration:

$i_{0}=z F k_{0}[O x][R e d]$

where $k_{0}$ is the kinetic constant of the reaction, and $[O x]$ and $[R e d]$ are the concentration of the oxidized and the reduced species respectively. In the case of acid copper plating, $k_{0}$ is equal to $1.10^{-4} \mathrm{~cm} / \mathrm{s}$ (Takahashi 2000).

Finally, considering that a current-potential curve can be approximated by a linear law in low over-potential and using the Tafel relation for the transfer coefficient, $\alpha$ can be determined experimentally as follows:

$b=\frac{2.303 R T}{(1-\alpha) z F}=\frac{\Delta \eta}{\Delta \log |i|}$

The value of $i_{0}$ (Eq. 4) can be determined from the graph in Fig. 3 by extrapolating the curves to $\eta=0$, when $\log i=$ $\log i_{0}$. The constant is obtained by fitting the $\log (i)$ versus $\eta$ curve.

\section{Aging model}

The aging process is complex and there are many factors that can affect it. A poor-quality coating may reduce the useful life of the processed product, due, for example, to corrosion, or fatigue rupture.

\section{Solution factors}

Solution aging can occur due to parameters variation during service or by secondary reactions that may lead to the degradation of products, as it directly affects the final coating properties (Dini and Snyder 2010). The quality services in industries perform maintenance control checks of these parameters within a defined frequency (preventive maintenance). Generally, the factors that indicate the electrolytic bath is in a poor state are: excess $\mathrm{H}_{2} \mathrm{SO}_{4}$, missing $\mathrm{H}_{2} \mathrm{SO}_{4}$, overly high bath temperature, lack of copper in solution, anodes turned to passives, inorganic contamination, and the presence of organic products. In practice, the last three parameters cannot be monitored.

\section{Coating factors}

Coating properties depend on many parameters, such as the distribution of current lines in the electrolyte, cathodic current density, bath agitation and temperature, saline concentration, $\mathrm{pH}$, hydrogen concentration, bath composition and concentration, scouring, water ohmic resistance, lack of filtering, and bath contamination.

Coating defects can lead to product failure during service, due to the fact that the product's properties do not correspond to the expected ones. These defects can be detected by observing the surface aspect, and determining if there is poor adherence, thinness, or corrosion of the coated product.

In practice, each factor mentioned above requires the coating process to be halted. As such, it is important to monitor both the bath and the coating results. Several methods can be employed to do this. In this study, the proposed method aims to identify parameters to which the process is suitably sensitive and that are sufficiently representative of the aging process of the solution and the quality of the coating surface.

\section{Parameter variation models}

A parameter variation model is proposed to select one or more parameters to monitor and study its variation and relation to the aging process. This model is derived from the nominal model and the failure studies documented in previous research (Paunovic and Schlesinger 2006). In this section, a short overview of previous research is presented. Two possible solutions are presented as an analytical model and as an 


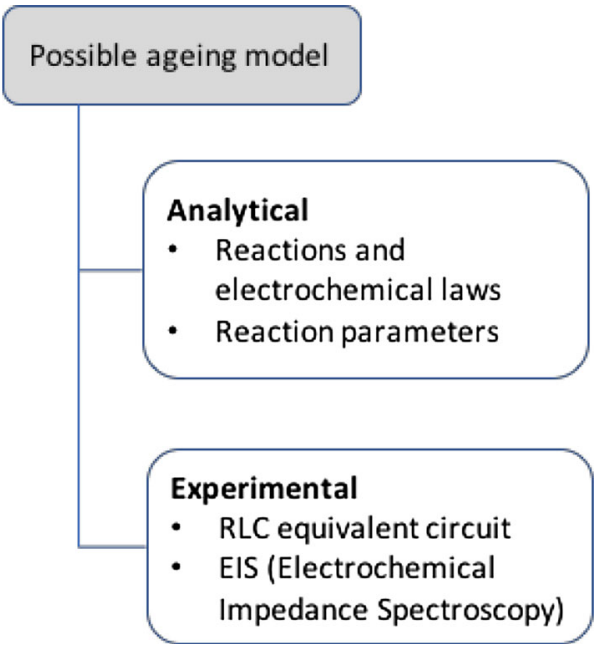

Fig. 4 Analytical and experimental parameter variation models

experimental parameter variation model (Fig. 4). The analytical model is close to the nominal model described above. Conversely, the experimental parameter variation model, based on electrochemical impedance and the equivalent electrical circuit theory, shows a complete characterization of the aging process but with a complex relation to the nominal model (Gabrielli et al. 2004, 2006, 2008).

The analytical model presented in Eqs. 3 and 4 provides a way to monitor the $\mathrm{Cu}^{2+}$ concentration in the solution. In this model, it is possible to describe the current or potential variation related to the concentration. This work focuses on the most sensitive aging process rather than any others mentioned in the literature (Dini and Snyder 2010). In this study, the $\mathrm{pH}$ dependency is not considered high if it falls between the acceptable upper and lower limits. Also, the temperature is not considered to be a factor because its range variation during the process will be small. Finally, the acid copper solution is more tolerant of ionic impurities than many other plating solutions.

Drawing on the works outlined above, the authors present a method to reveal the solution aging and thus the process quality status.
The Butler-Volmer equation, Nernst equation, and density current to concentration dependency are used to track the $\mathrm{Cu}^{2+}$ concentration (Fig. 5).

The constants in the equation can be experimentally found or obtained from tables. The parameters that would change with the concentration are marked with an arrow, and their corresponding laws are shown. This model represents the expected response of the process to different copper concentration values.

The second method that can be used to model electrochemical interfaces considers the process that occurs in the interface between the metal and the electrolyte as a component of an electrical circuit. The Electrochemical Impedance Spectroscopy (EIS) method considers the electrochemical impedance of the electrode (voltage/current ratio) as a transfer function (Gabrielli et al. 2006), and uses the frequency domain. This is an experimental model that requires validation with respect to the process, as well as correlation between the components of the model and the real physicochemical behavior (Gabrielli et al. 2006; Macdonald et al. 1998). The theory of the reactions and their effects on the process is complex. Some publications have worked on the relation of the electrochemical impedance output and the actual degradation with complex mathematical models (Gabrielli et al. 2006) or by using experimental correlation (Yu et al. 2015).

Models based on EIS require full knowledge of the process and its reactions, and as such, none of these methods were used here to investigate the parameter monitoring.

In this work, the analytical aging model is chosen as the final aging model. The experimental model, based on electrochemical impedance, is discarded because it lacks a validation method linked with the nominal model.

\section{Application and results}

\section{Experimental platform}

An electrochemical platform is designed to measure and impose the current and the potential. This experimental plat-

$$
\begin{aligned}
& \rightarrow \boldsymbol{\eta}=E-E_{0} \longrightarrow E_{0}\left(\left[C u^{2+}\right]\right)=\overline{E_{0}}+\frac{R T}{z F} \log \left[C u^{2+}\right] \\
& i(\boldsymbol{\eta})=i_{0}\left[e^{\frac{(1-\alpha) z F \boldsymbol{\eta}}{R T}}-e^{-\frac{\alpha z F \boldsymbol{\eta}}{R T}}\right] \\
& \rightarrow i_{0}\left(\left[C u^{2+}\right]\right)=z F k^{0}\left[C u^{2+}\right]^{\alpha}
\end{aligned}
$$

Fig. 5 Equations used to monitor the parameters' variation 


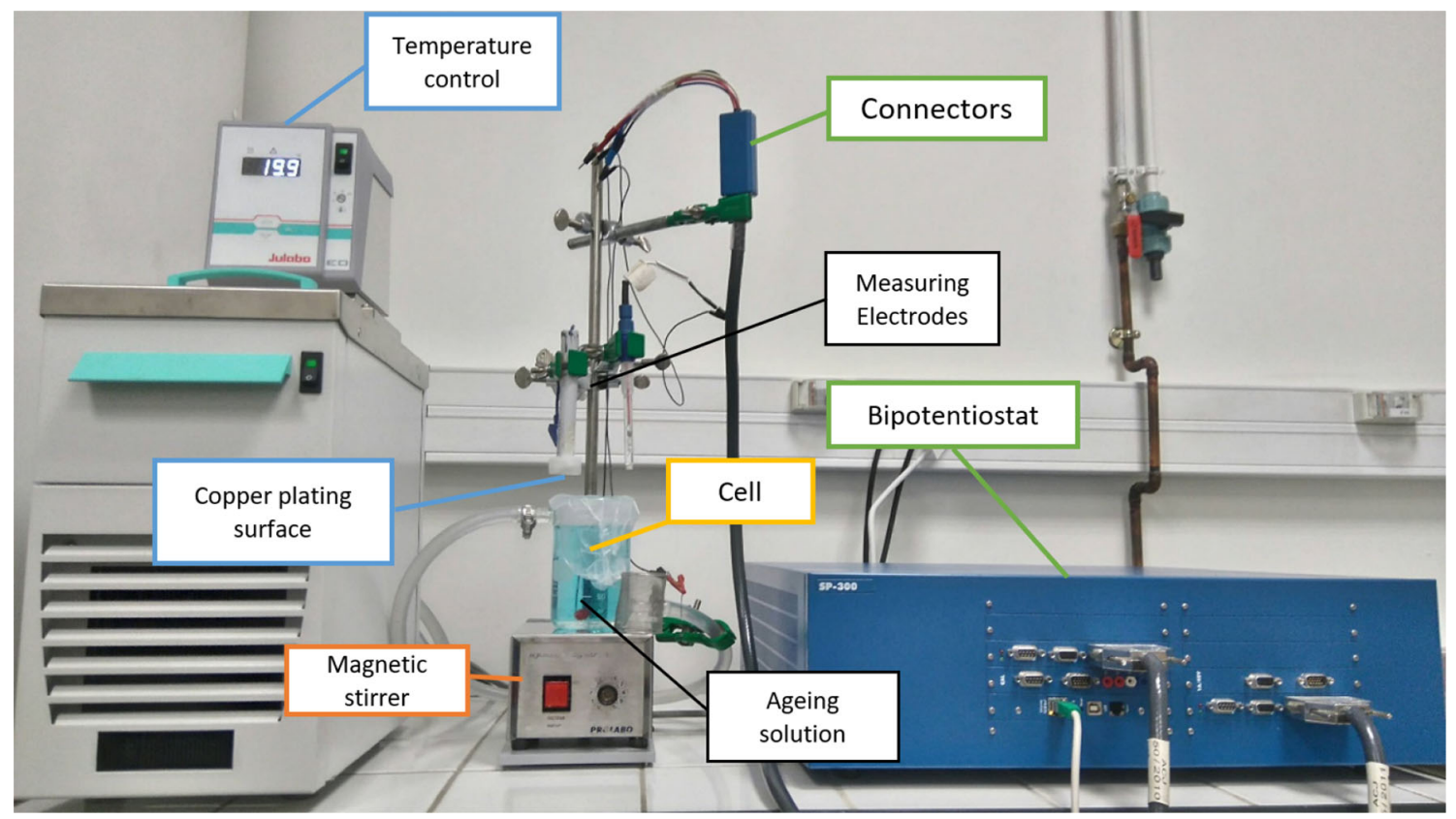

Fig. 6 Test bench

form is composed of an electrochemical cell, connectors for electrodes, an acquisition software EC-Lab with the capacity to create experiments to be performed online, and a bipotentiostat (Fig. 6).

The cell temperature is controlled by an automatic water thermostat table. The deposition process is monitored by a potentiostat, connected to a PC to acquire the data. The potentiostat can impose the current for the deposition and also measure the potential during the experience. All potential values are measured in reference to a calomel electrode.

The EC-Lab acquisition software is used to interact with the electrochemical process and measure the parameters of interest. EC-Lab can run any MATLAB script in between the experiments in order to perform the analysis of the data and show the output via a Graphical User Interface (GUI), presenting acquired data information and analysis such as current values and predictions.

\section{Working hypotheses}

In this work, the authors investigate the following statements.

- The cooper concentration level is a risk for the plating process. The process is based on the copper reduction on the surface of the cathode. This converts the copper to a solid state and thereby creates a thick film of copper coating. In case of absence of copper(II) on the surface, the process becomes impossible and the plating fails. The tendency of this parameter should be a negative exponential, for which the order is unknown, related to the Faraday law of the speed of the reaction.

- The mathematical model describes the relationship between the concentration and the measurable parameters. The potential measured between the cathode (coat surface) and the reference electrode is dependent on a variety of parameters. One of those is the copper concentration on the surface during the process. This parameter can be isolated by keeping all the other parameters (geometry, surface reactive additives, $\mathrm{pH}$, chloride presence, passivity of the anode, and changes in temperature) constant. This also means that, during the process, any control or regeneration is performed only in order to see the variation of the monitored parameter.

- Contaminants are not considered. Contamination causes changes in the parameters of the equation used in this parameter variation model. The process is independent of this kind of aging and the parameter considered here is only the copper concentration. Moreover, some contaminants can cause secondary reactions that lower the copper concentration.

\section{Measured parameters}

In the nominal process, the concentration values are measured in order to find the relation between the chosen parameter to be measured and the process parameter which is representative of the aging. As shown in Fig. 7, the potential is the monitored parameter and the copper concentration at the cathode surface is the aging parameter. 


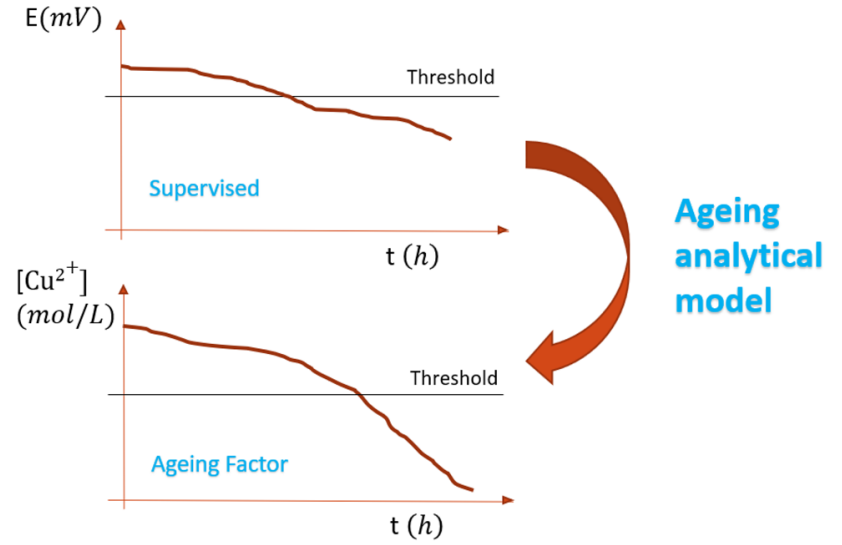

Fig. 7 Comparison between the monitored parameter (top) and the aging parameter (bottom)
The nominal model presented in "Nominal model" and "Parameter variation models" sections is used to calculate the nominal and aged values.

By adding the overpotential $\eta$, shown in Fig. 8, and the potential $\mathrm{E}_{0}$, it is possible to obtain a third parameter that facilitates monitoring (E). Concluding this section, it is evident that the variation of the monitored value is small (around $300-400 \mathrm{mV}$ ). This means that any noise (generally tens of millivolts) higher than this value should be filtered during the data acquisition stage. It is also necessary to select a low voltage working point to make the variation relevant given the nominal voltage value.

The selected model is valid for $\eta$ values higher than $100 \mathrm{mV}$, which means that the variation of the monitored value can represent as much as $400 \%$ or lower of the nominal value (see the working point in Fig. 9).

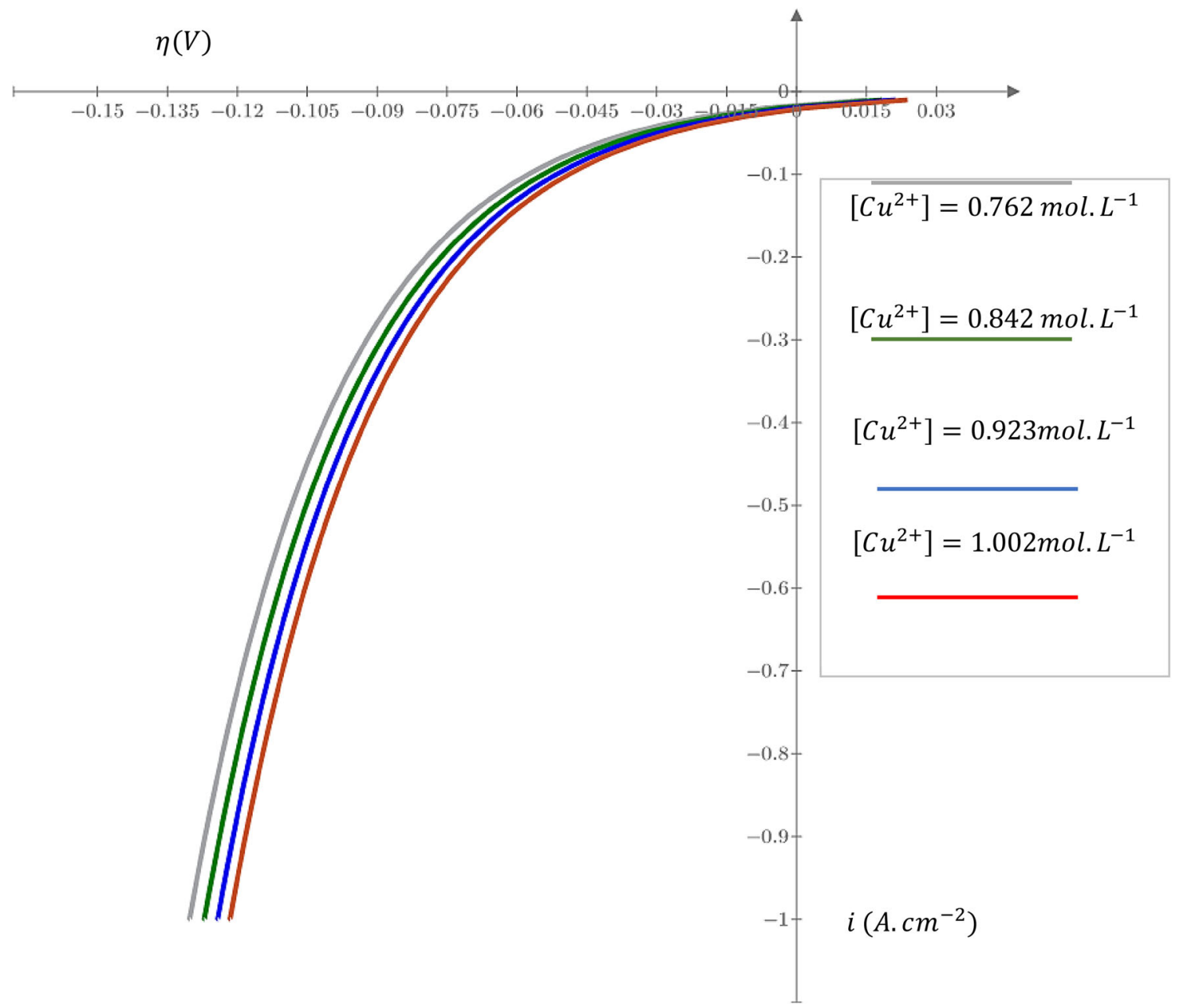

Fig. 8 Variation of the parameters in the Tafel curve and effect of the copper concentration on the transfer current and potential E 


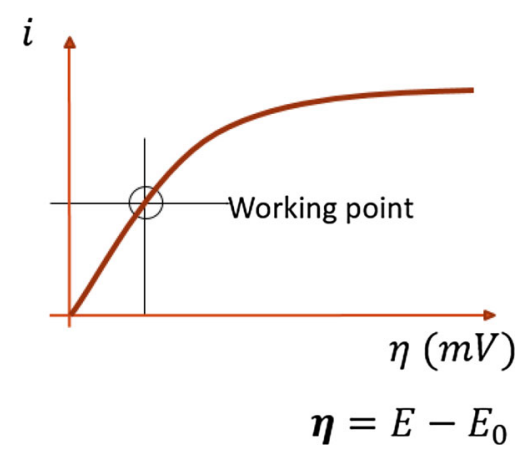

Fig. 9 Working point in Tafel equation

\section{Aging model and RUL estimation}

The prediction model consists of an exponential regression updated for each new point acquired. Its coefficients are calculated for best fit to the last recorded data. Once the regression model is obtained, the monitored parameter val- ues are calculated in order to obtain the RUL value (Fig. 10). This is achieved using the fit function in MATLAB. The kind of function selected to fit the aging model formula is related to the physical Faraday formula that describes the speed of reactions. The variation of the monitored parameter is linked to the reaction speed, and so the aging model that can best represent this variation is in fact the same model that represents the concentration variation. The implication of this aging model is that the concentration law is also a double exponential.

\section{Experiments}

Conducting experiments allowed the validation of the theory framework and the evaluation of the hypotheses presented in this work. The ultimate goal was the validation of the parameter variation model and the calculation of RUL values (Fig. 11). The following subsections present the validation of the double exponential model.

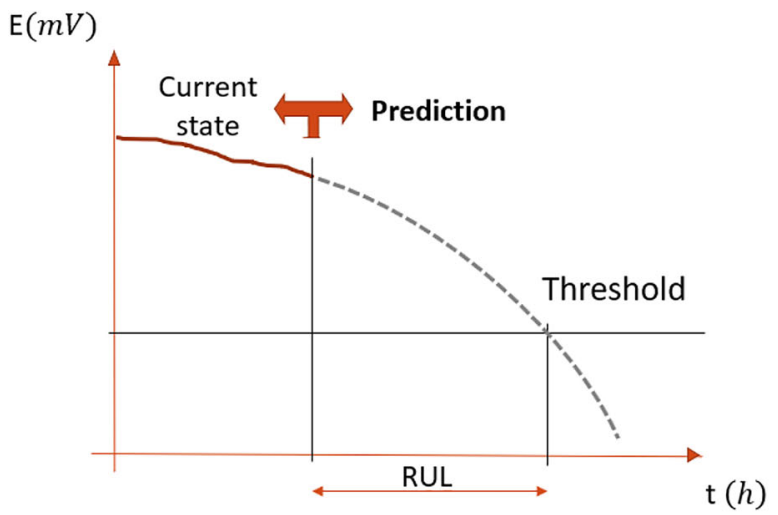

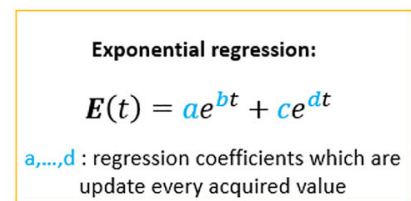

update every acquired value

Fig. 10 RUL estimation using the supervised value

Threshold \&

RUL calculation

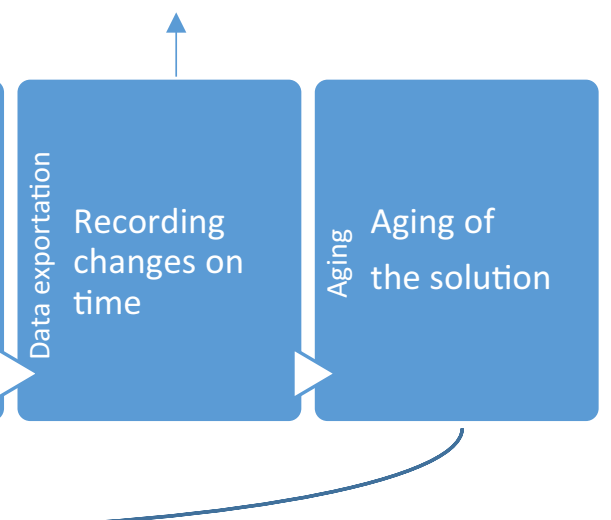

Fig. 11 Experiment steps 


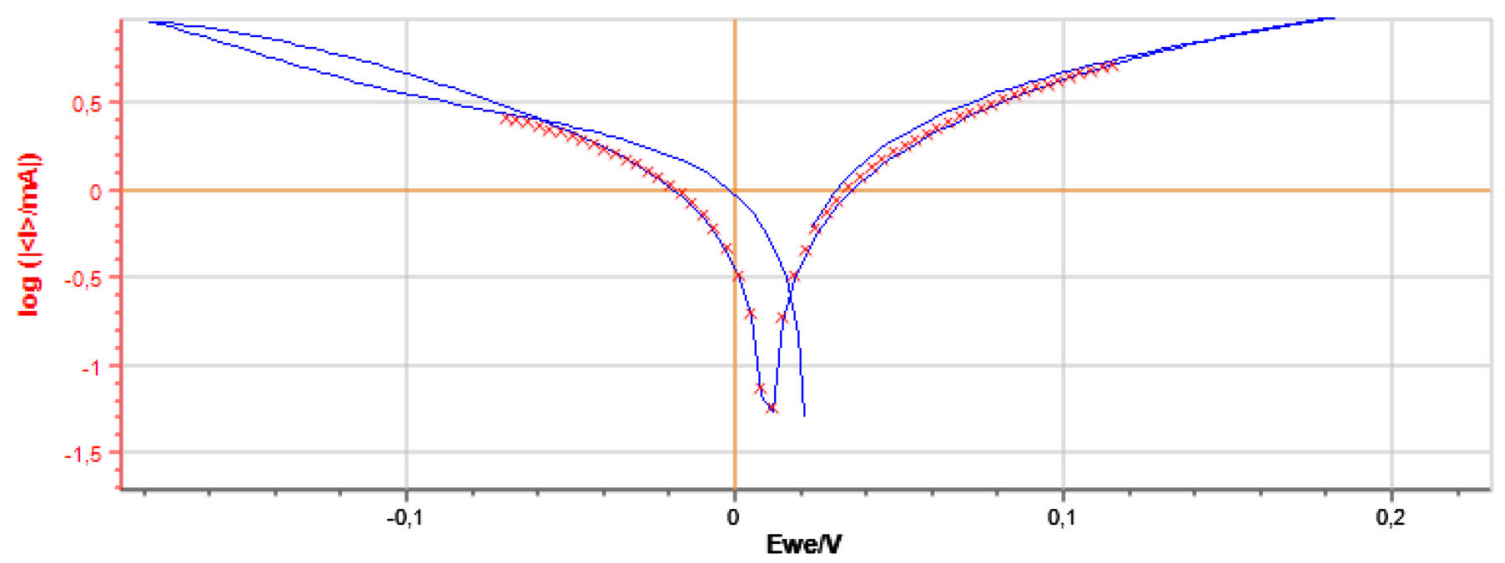

Fig. 12 Tafel fit to obtain the parameters for the parameter variation model

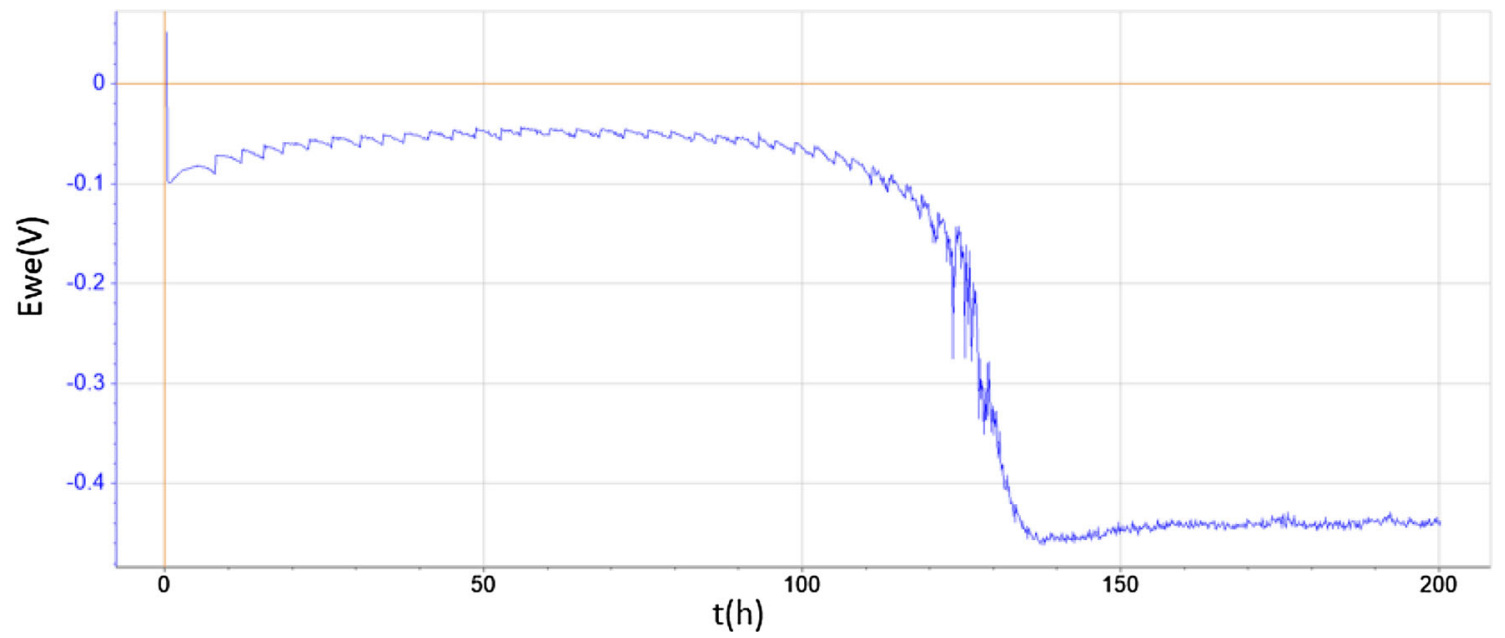

Fig. 13 Chronovoltammetry to characterize the process

Fig. 14 Copper deposit: surface approximately $10 \mathrm{~mm}^{2}$, and approximately $5 \mathrm{~mm}$ thick
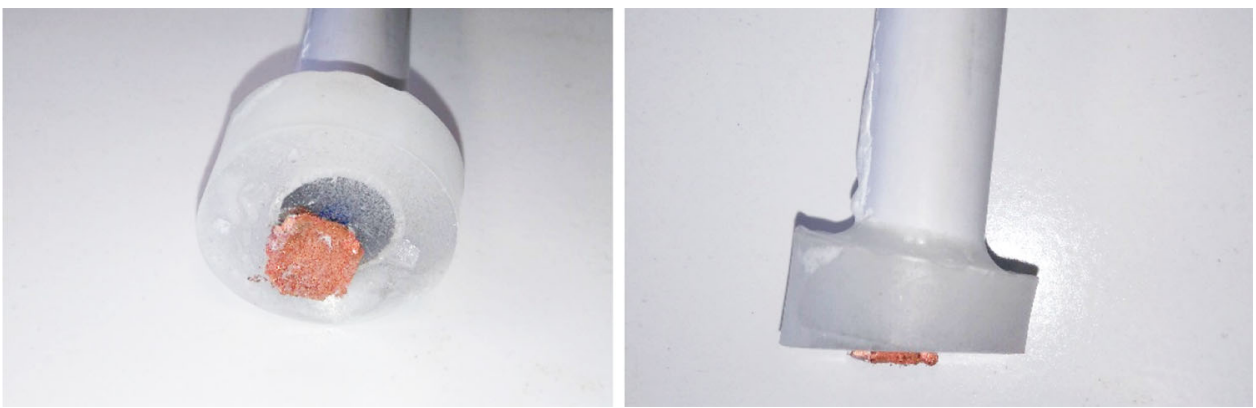

\section{Procedure description}

The cell is prepared for every experiment with the same concentration of $\mathrm{CuSO}_{4}$ and $\mathrm{H}_{2} \mathrm{SO}_{4}$. The working electrode surface is polished to avoid adherence problems. The $\mathrm{pH}$ is always kept lower than 3 .

During the process, a Tafel fit (provided by the EC-Lab software) is performed to obtain the initial conditions: $\mathrm{i}_{0}, \mathrm{E}^{\circ}$,
$\mathrm{C}^{2+}$ concentration, and $\alpha$ (Fig. 5). After this, and with the initial values, the model is run in MathCAD to determine the potential limit at which the concentration variation drops down to zero. The threshold for the RUL calculation (the results of which are presented in "Application and results: RUL calculation" section) is established as $50 \%$ of this potential variation. This threshold is applied to the monitored value (potential between the reference electrode and the working 
Table 2 List of experiments

\begin{tabular}{lllll}
\hline Experiment & File name & Duration $(\mathrm{min})$ & Temperature $\left({ }^{\circ} \mathrm{C}\right)$ & RUL calculation \\
\hline 1.1 & Constantcurrent10 & 6697 & 20 & - \\
1.2 & Constantcurrent11 & 7708 & 20 & See Fig. 18a \\
1.3 & Constantcurrent12 & 4202 & 20 & - \\
2.1 & Constantcurrent13 & 3667 & 22.5 & See Fig. 18b \\
2.2 & Constantcurrent14 & 7583 & 22.5 & - \\
2.3 & Constantcurrent15 & 5000 & 22.5 & - \\
3.1 & Constantcurrent16 & & 25 & See Fig. 18c \\
3.2 & Constantcurrent17 & & 25 & - \\
3.3 & Constantcurrent18 & & 25 & - \\
\hline
\end{tabular}

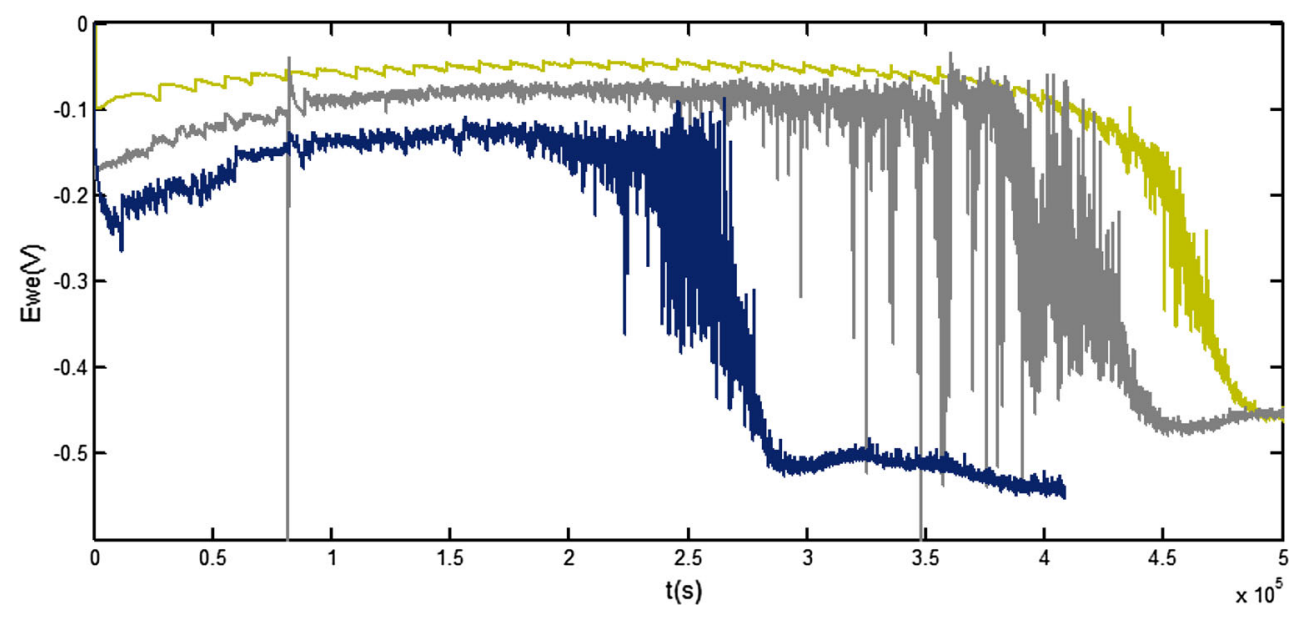

Fig. 15 Experimental campaign $1-\mathrm{T}: 20^{\circ} \mathrm{C}$

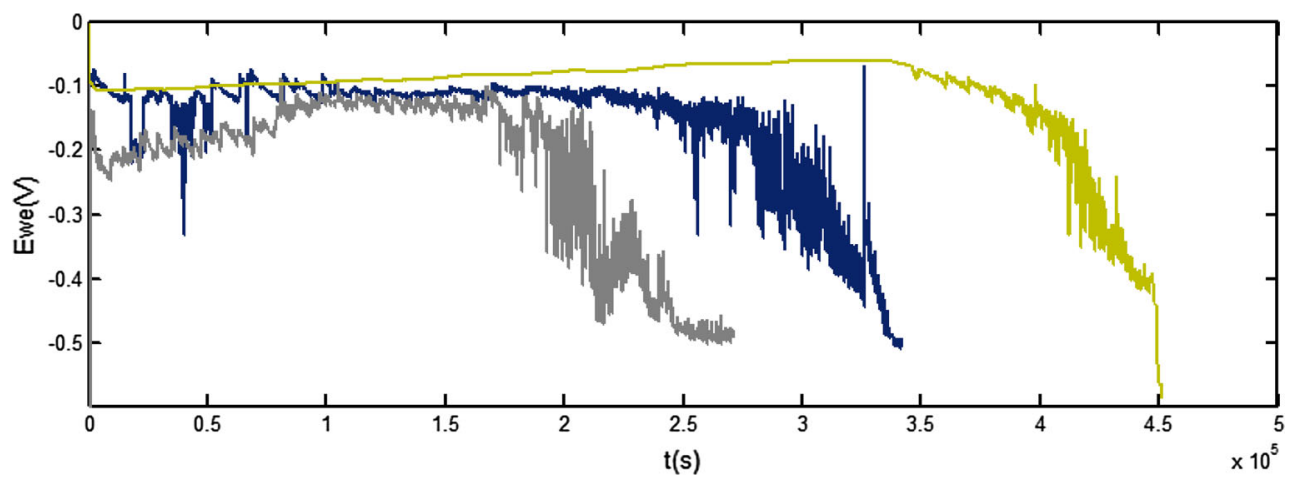

Fig. 16 Experimental campaign $2-\mathrm{T}: 22.5^{\circ} \mathrm{C}$

electrode). Chronopotentiometry is performed to record the potential every $1 \mathrm{~s}$ and the data are written to a text file created on the hard disk of the computer connected to the potentiostat. The experiment stops after the potential limit calculated by the parameter variation model is achieved. The current density is fixed at around $100 \mathrm{~A} / \mathrm{m}^{2}$ in all the experiments, so as to be in the Tafel area of the I versus E curve.

Three experimental campaigns are carried out, each using a different working temperature, and all the steps are repeated three times per temperature condition, to detect variability in the results. In total, nine experiments are conducted. To reduce the run time of the experiment (and thereby get a result faster), the initial concentration of the solution is kept low: only $6.6 \%$ of the nominal value ("Physicochemical process" section).

The first experiment is used to corroborate the parameters of the process and for comparison with the nominal model. After the Tafel fit (Fig. 12), the parameters for the parameter 

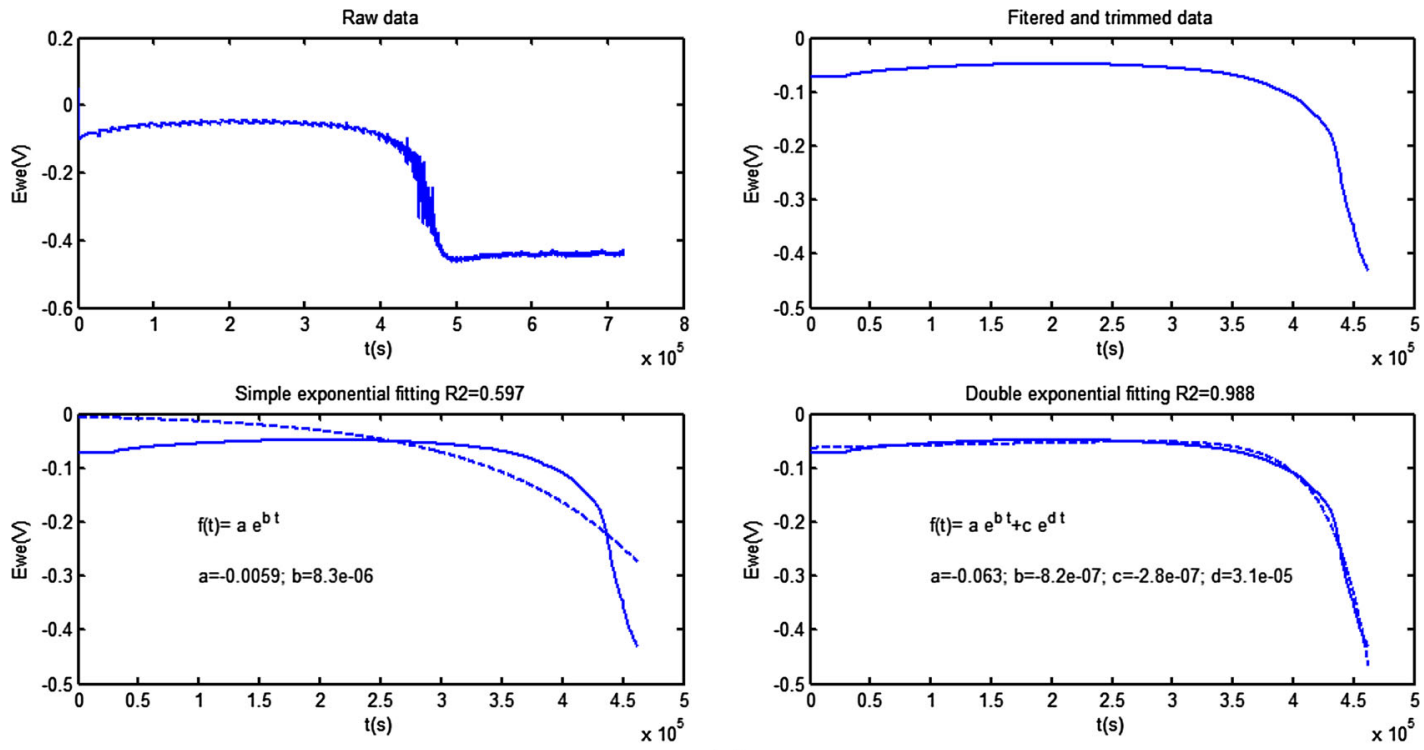

(a)
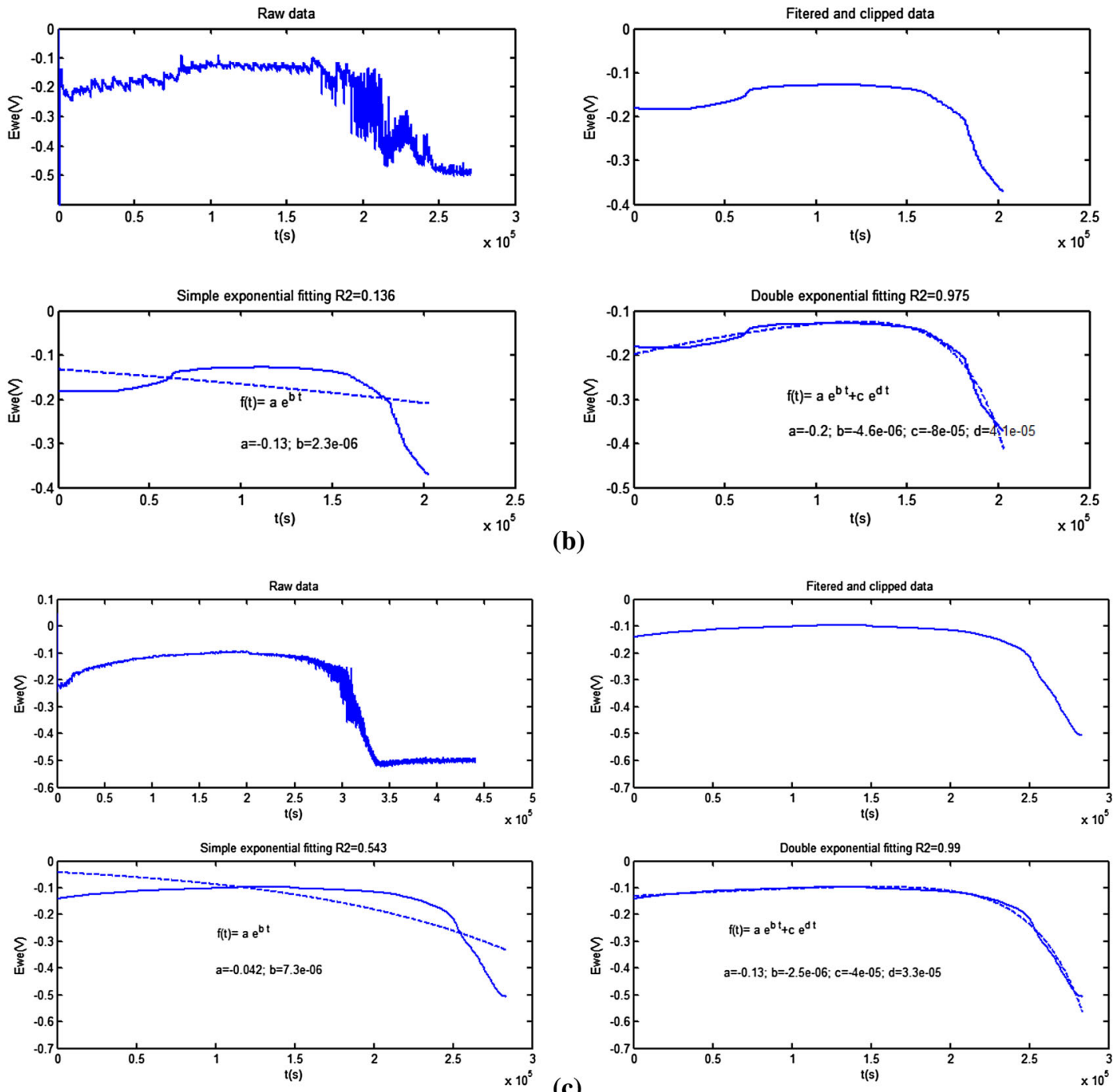

Fig. 17 Data and model with R-squared coefficient for experiments $1.2(\mathbf{a}), 2.1(\mathbf{b})$ and $3.1(\mathbf{c})$. The raw and the filtered data are shown on the top. Two fitting options are shown in the bottom for each subfigure: simple exponential fitting and double exponential fitting 
Table 3 Prediction model for each experiment. The threshold is the value to reset to the initial potential of the experiment

\begin{tabular}{|c|c|c|c|c|c|}
\hline Experiment & Prediction model & Coefficients & & R-squared & $\begin{array}{l}\text { Threshold for RUL } \\
\text { calculation }\end{array}$ \\
\hline 1.1 & $f(t)=a e^{b t}+c e^{d t}[V]$ & $\begin{array}{l}\mathrm{a}=-0.12 \\
\mathrm{~b}=-2.2 \mathrm{e}-06\end{array}$ & $\begin{array}{l}\mathrm{c}=-4.2 \mathrm{e}-06 \\
\mathrm{~d}=2.8 \mathrm{e}-05\end{array}$ & 0.953 & $-170 \mathrm{mV}$ \\
\hline 1.2 & & $\begin{array}{l}\mathrm{a}=-0.063 \\
\mathrm{~b}=-8.2 \mathrm{e}-07\end{array}$ & $\begin{array}{l}\mathrm{c}=-2.8 \mathrm{e}-07 \\
\mathrm{~d}=3.1 \mathrm{e}-05\end{array}$ & 0.998 & - \\
\hline 1.3 & & $\begin{array}{l}a=-0.19 \\
b=-2.7 e-06\end{array}$ & $\begin{array}{l}c=-8.3 e-06 \\
d=4.1 e-05\end{array}$ & 0.971 & - \\
\hline 2.1 & $f(t)=a e^{b t}+c e^{d t}[V]$ & $\begin{array}{l}\mathrm{a}=-0.20 \\
\mathrm{~b}=-4.6 \mathrm{e}-06\end{array}$ & $\begin{array}{l}c=-4.6 e-07 \\
d=3.5 e-05\end{array}$ & 0.975 & $-270 \mathrm{mV}$ \\
\hline 2.2 & & $\begin{array}{l}\mathrm{a}=-0.10 \\
\mathrm{~b}=-2.1 \mathrm{e}-06\end{array}$ & $\begin{array}{l}c=-4.6 e-07 \\
d=3.5 e-05\end{array}$ & 0.981 & - \\
\hline 2.3 & & $\begin{array}{l}\mathrm{a}=-0.11 \\
\mathrm{~b}=-1.2 \mathrm{e}-06\end{array}$ & $\begin{array}{l}c=-5.3 e-04 \\
d=2.4 e-05\end{array}$ & 0.985 & - \\
\hline 3.1 & $f(t)=a e^{b t}+c e^{d t}[V]$ & $\begin{array}{l}\mathrm{a}=-0.11 \\
\mathrm{~b}=-1.2 \mathrm{e}-06\end{array}$ & $\begin{array}{l}c=-5.3 e-04 \\
d=2.4 e-05\end{array}$ & 0.990 & $-198 \mathrm{mV}$ \\
\hline $\begin{array}{l}3.2 \\
3.3\end{array}$ & & & & & \\
\hline
\end{tabular}

variation model shown in "Parameter variation models" section are set, and a threshold is obtained for each experiment.

Firstly, the correctness of the average value of the expected voltage limit is corroborated using the chronovoltammetry curve in the reduction stage. Figure 13 presents the chronovoltammetry data that facilitated the characterization of the process. It reveals a $392 \mathrm{mV}$ diminution that can be compared with the $380.16 \mathrm{mV}$ of the parameter variation model analysis. The time elapsed from the starting concentration of $100 \%$ to the ending concentration of $0 \%$ is $80 \mathrm{~h}$.

Figure 14 presents the electrode surface after the electroplating process, revealing the copper deposit.

\section{Application and results: RUL calculation}

After model verification, the test bed is run for approximately $200 \mathrm{~h}$ per experiment to obtain a degradation variation of the solution quality. At the end of each experiment (Table 2), we can verify the parameter tendency and correlate this to the expected values of the monitored parameter. The solution is transparent at the end of each experiment, which verifies the absence of $\mathrm{Cu}^{2+}$.

During the experiments (Figs. 15, 16), the plating changes the surface, making it bigger and providing more active areas to reduce the copper ions. This effect creates a positive tendency of the monitored parameter that was not taken into account. Furthermore, variation of the aging parameter is expected at the end of the experiment, but with a different starting value.
As outlined in "Experimental platform" section, a MATLAB program (or script) is developed for the data processing and analysis, and is responsible for a number of functions outlined here. The original frequency is set to 1 point per second and the script analyses the data at a frequency equal to 1 point per minute. Signal clipping is performed, removing the first $5 \mathrm{~h}$ of experimental data to exclude any initial noise when calculating the prediction model. The script clips the end data where the signal is stable, as these are of no use to the prediction model. It is also responsible for filtering the data, using a media filter with an order of 500 (meaning that each filtered data point is calculated using the average of its 500 neighbor points, representing around $20 \%$ of the total points). The last task performed by the script is obtaining the prediction model with its parameters. Goodness of fit is evaluated by the R-squared parameter, which is always kept higher than 0.95 when the complete data per experiment are used. The derived model is similar to that shown in the previous section. Figure 17 presents the results obtained after running the script with the whole data series.

The R-squared fitting parameter is mostly stable and is always over 0.91 during the calculations, which indicates a good fit for the data and a representative prediction model. These results show how the selected prediction model updates its coefficients to best fit the online measurements. As expected, the model represents an exponential decrement showing a second-order reaction speed.

Finally, the analysis of the parameter values of the prediction function, which are close to each other, confirms that the 


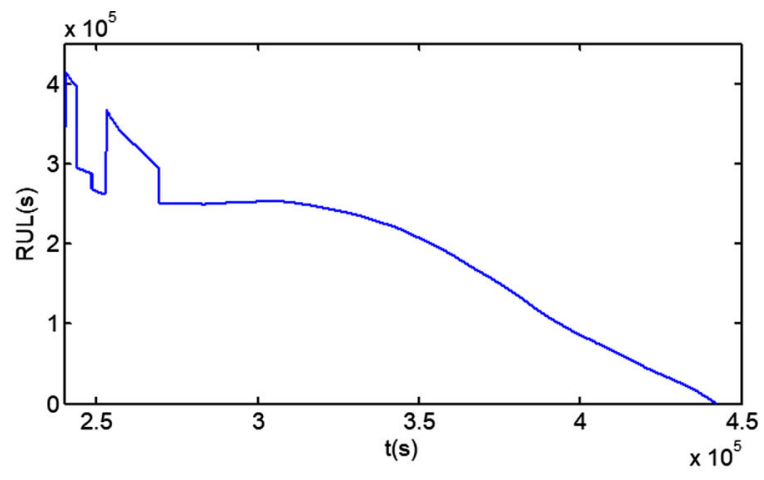

Prediction function parameters
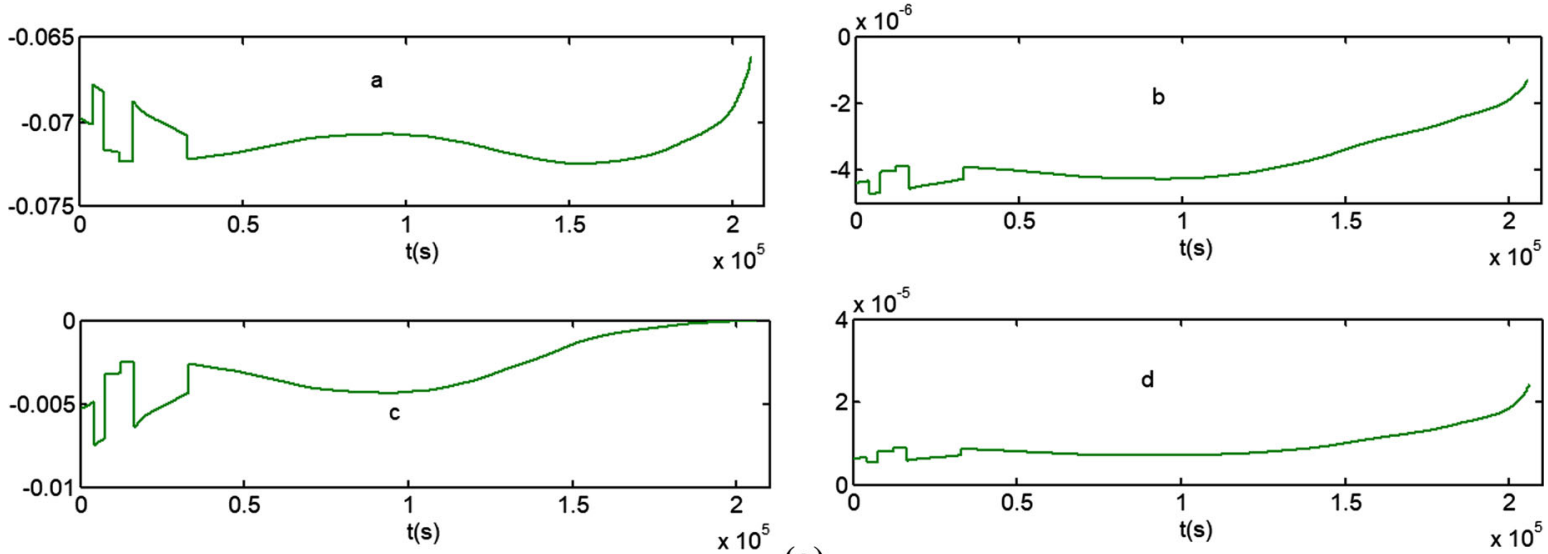

(a)

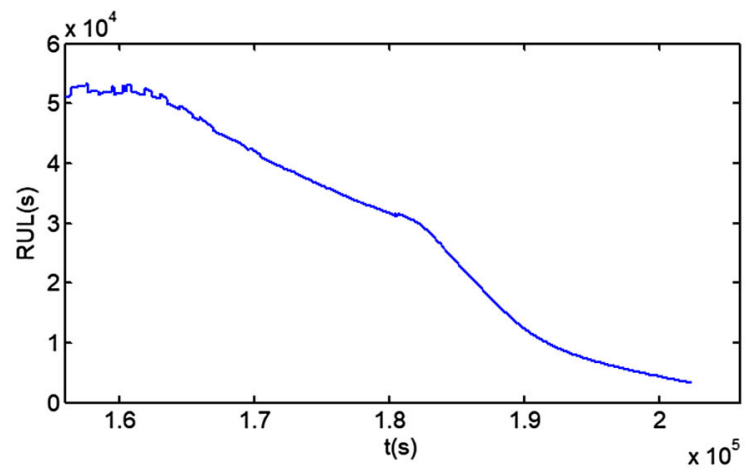

Prediction function parameters
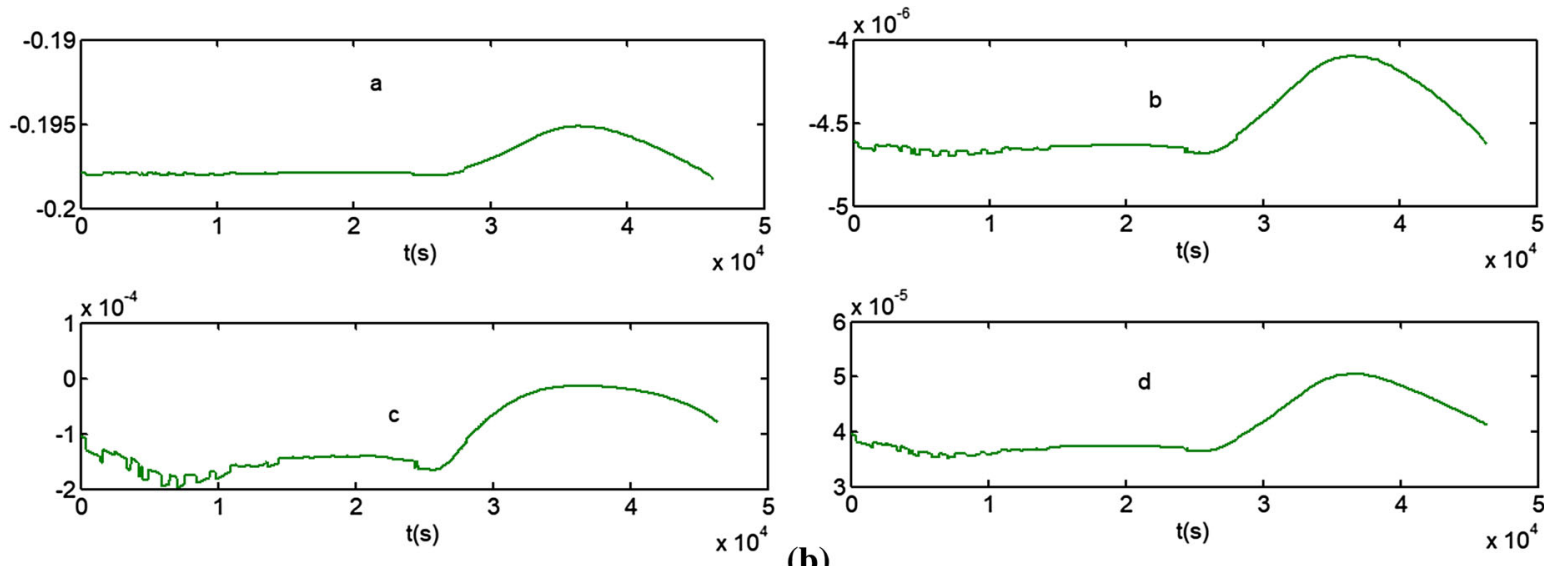

(b)

Fig. 18 RUL calculation with parameter variation during the calculation for experiments 1.2 (a), 2.1 (b), and 3.1 (c) 

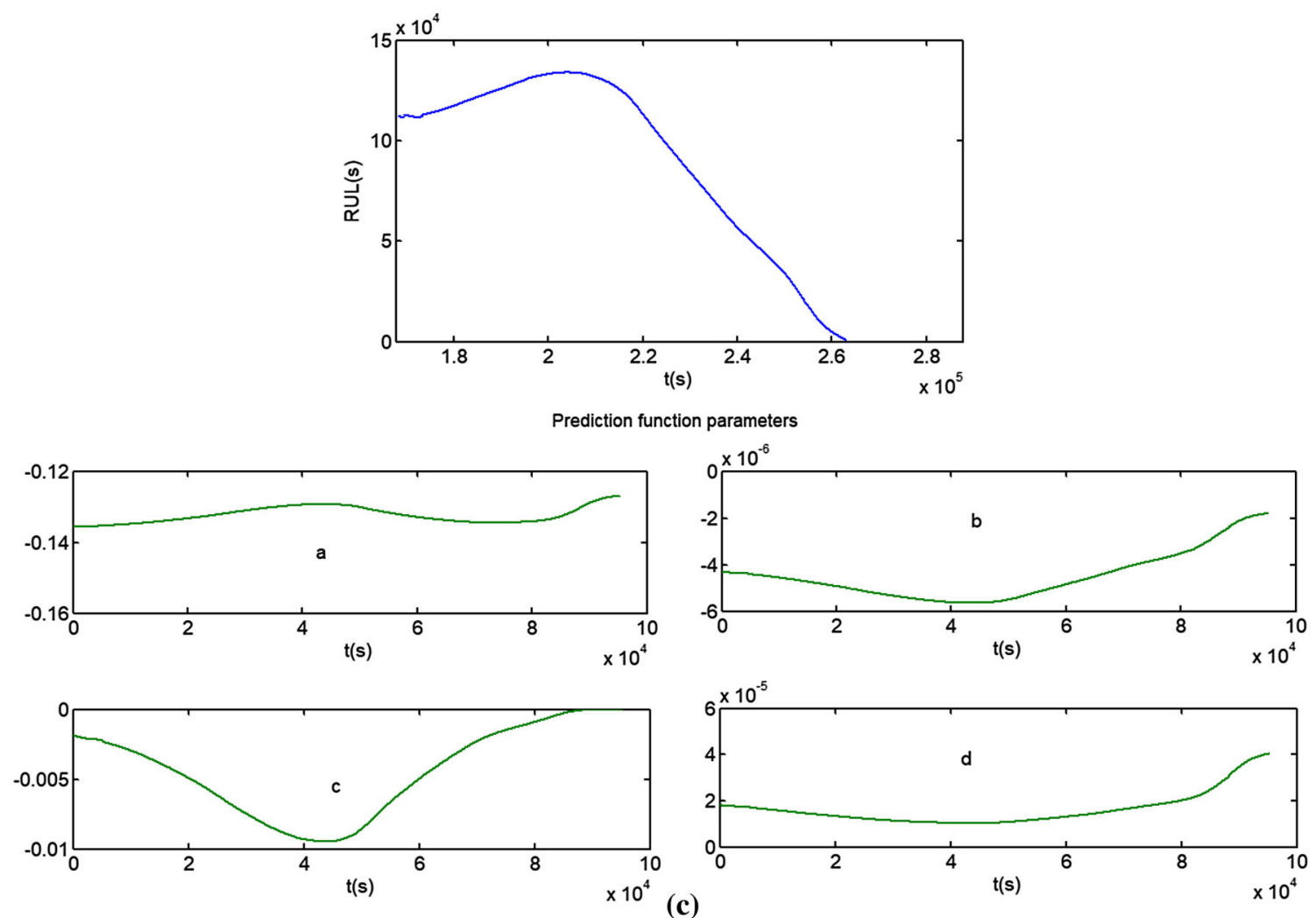

Fig. 18 continued

double exponential model represents the aging of the electrochemical process well (Table 3).

Another script is run to calculate the RUL of each experiment per campaign. This script creates a GUI output during the calculation that allows to monitor the experiment and see the data together with the prediction function and the threshold position. The goal is to simulate an online acquisition by showing the RUL versus time graph. After the experiments, this script is run with the clipped and filtered data obtained from the previously described script. Alternatively, the online acquisition data can be read directly from EC-Lab with this script by filtering the online data. An estimation of the RUL is made every $60 \mathrm{~s}$ and calculated to a $60 \mathrm{~s}$ precision. Due to the fitting script limitations, the first 10 points are not predicted but are used to start the fitting and seed the subsequent predictions. A part of the script controls the constant analysis of the acquired data to avoid two potential prediction failures that could halt the program. The first such failure is where a large RUL value is obtained due to the low negative tendency of the prediction model. This is a computing time limitation because the prediction function is calculated versus time until it reaches the threshold. The second such failure is where the prediction model develops a positive tendency and hence the function can never reach the lower threshold. The script jumps past any points that might cause these problems and starts RUL calculation again at the next unproblematic point. To do this, derivative values are continuously calculated and analyzed to confirm the data tendency at the beginning and during all the calculation. Indeed, the RUL estimation is launched only after observing that the solution quality is decreasing, which is verified by a negative tendency in the curve representing its time evolution. These security measures avoid the script crashing and allow it to decide where to continue. At the end of the calculation, the RUL and the variation of the prediction model coefficients' tendency are obtained (Figs. 18, 19).

The first (top) graphs in Figs. 18a-c show the result of the RUL calculation for the experiments 1.2, 2.1, and 3.1. These figures show that the RUL calculation does not start from time zero, but after a negative tendency is observed in the experimental data. This corresponds to $2.4 \times 10^{5} \mathrm{~s}$, $1.55 \times 10^{5} \mathrm{~s}$, and $1.6 \times 10^{5} \mathrm{~s}$ for experiments $1.2,2.1$, and 3.1, respectively. The results in Fig. 18 also show fluctuations in the estimated RUL, especially at the beginning of the estimation. This is normal as the behavior of the solution, and consequently its quality, changes over time. Finally, among the three estimated RULs, the first two are shown to be the most stable over time, and more particularly when the experiment approaches its end. 

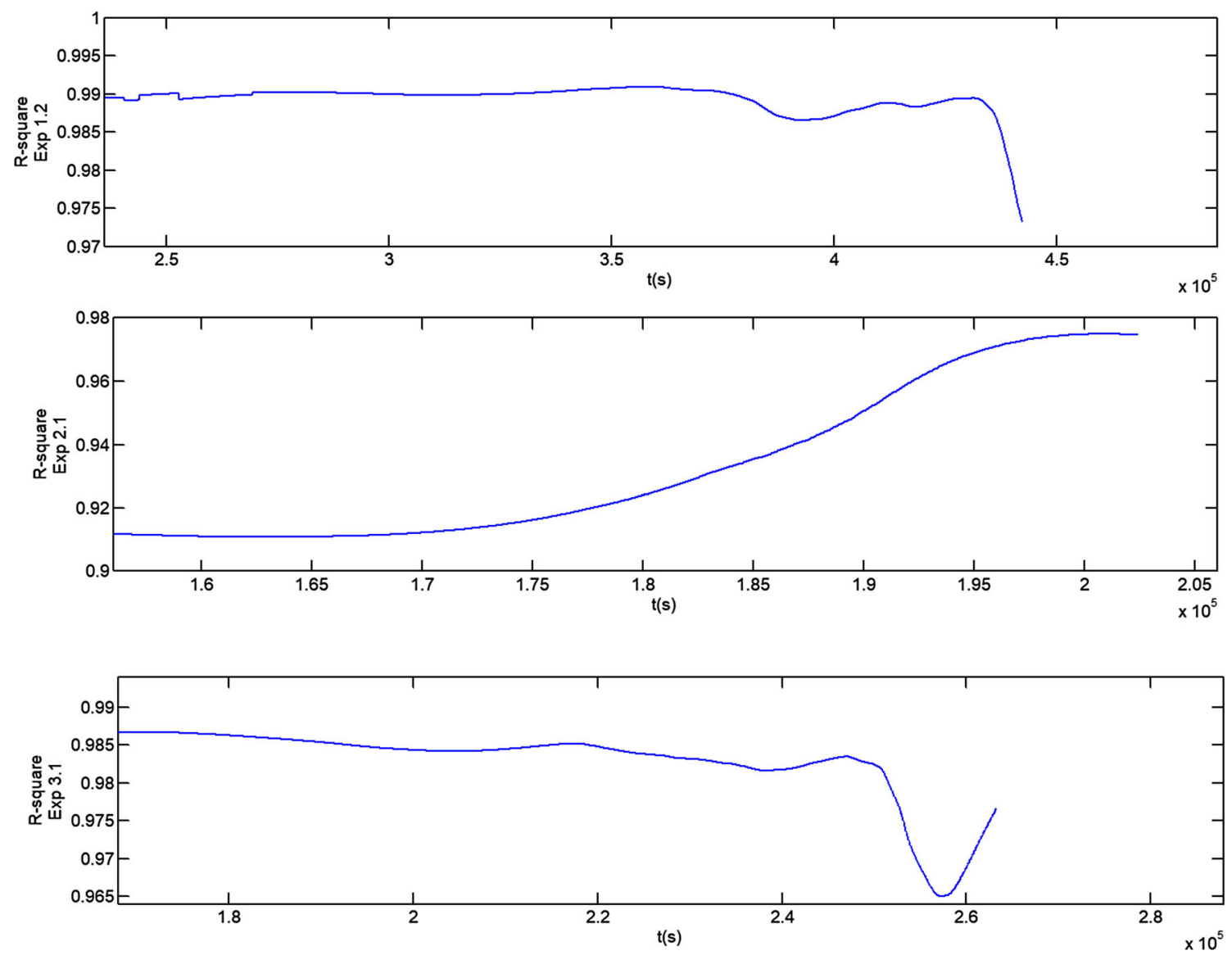

Fig. $19 \mathrm{R}$-squared variation during the calculation for experiments 1.2, 2.1 and 3.1 (from top to bottom)

It is noteworthy that the obtained data and results show a weak impact of temperature increase on the total duration of the experiments and consequently on the RUL. The parameters of the prediction function, $a, b, c$, and $d$ are variable during the calculation as shown in Fig. 18. Nevertheless, the RUL calculation seems more stable at the end than at the beginning. This classic behavior indicates that the prediction becomes more reliable with time.

\section{Conclusions and future work}

The present work has shown the effectiveness of monitoring and predicting the solution quality in an electroplating process, with a RUL assessment. This was achieved by selecting a set of parameters, to represent the aging process, and monitoring the potential variation during the plating to assess the concentration variation in the solution (the selected aging parameter). The monitored parameter variation with time is low, and the data acquisition platform must be accurate enough to capture small changes, which was achieved in this study. The proposed method was verified and validated offline on acquired experimental data, but it can also work online during the process operation. One approach to achieving this is to use prediction tools that can estimate online the model parameters, such as Particle Filter. This tool uses the online observations to update the model parameters, repeating the process continuously and using the obtained updated model to assess the current state of health and predict the RUL.

The aging model requires knowledge of the process constants before starting to monitor them. This means that monitoring must be continuous, otherwise the process should be recharacterized when restarted. In our case, the characterization is enabled by the Tafel curves calculated at the beginning of each experiment.

The plating surface morphology is another aging parameter. If the surface changes, such as occurrence of micrometric porosity or specific surface variation, then the measured potential could change. In such cases, if consequent variation of the surface area occurs, the model should be corrected by using the Faraday equation.

Other parameters can be added and modelled, such as secondary reactions produced by additives or contaminants at the surface appearing when the aging duration is long. As presented in the introduction, EIS and equivalent elec- 
trical circuit theory could be another way to monitor with new PHM methods, since it allows the integration of more aging parameters at once (such as polarization resistance, electrolyte resistance, and kinetic constants of each of the electrochemical reactions considered).

In conclusion, in this study a PHM method was applied successfully to global copper electroplating, which offers possibilities for manufacturing using local electroplating as a micro-additive layer and using the proposed method for monitoring.

\section{References}

Dini, J. W., \& Snyder, D. D. (2010). Electrodeposition of copper. In M. Schlesinger \& M. Paunovic (Eds.), Modern electroplating (5th ed., pp. 33-78). New York: Wiley.

Gabrielli, C., Moçotéguy, P., Perrot, H., Nieto-Sanz, D., \& Zdunek, A. (2006). A model for copper deposition in the damascene process. Electrochimica Acta, 51(8-9), 1462-1472.

Gabrielli, C., Moçotéguy, P., Perrot, H., Nieto-Sanz, D., \& Zdunek, A. (2008). An investigation of copper interconnect deposition bath ageing by electrochemical impedance spectroscopy. Journal of Appled Electrochemistry, 38(4), 457-468.

Gabrielli, C., Mocoteguy, P., Perrot, H., Zdunek, A., Bouard, P., \& Haddix, M. (2004). Electrochemical Impedance spectroscopy investigation of bath aging in damascene process chemistries. Electrochemical and Solid-State Letters, 7(3), C31.

Gabrielli, C., Mocoteguy, P., Perrot, H., Zdunek, A., \& Nieto-Sanz, D. (2007). Influence of the anode on the degradation of the additives in the damascene process for copper deposition. Journal of the Electrochemical Society, 154(3), D163.

Gouriveau, R., Medjaher, K., \& Zerhouni, N. (2016). From prognostics and health systems management to predictive maintenance 1: Monitoring and prognostics. New York: Wiley-ISTE. ISBN 978-1-84821-937-3.

Imai, S. I., \& Kitabata, M. (2009). Prevention of copper interconnection failure in system on chip using virtual metrology. IEEE Transactions on Semiconductor Manufacturing, 22(4), 432-437.

Imai, S. I., Kitabata, M., \& Tanaka, T. (2009). Interconnection failure caused by bath degradation in copper electroplating and its VM-FDC using mathematical model. In Advanced semiconductor manufacturing conference (ASMC), (pp. 254-258).

Jaworski, A., Wikiel, H., \& Wikiel, K. (2011). Voltammetry coupled with multiway chemometrics for monitoring and diagnosis of electrodeposition process. Electroanalysis, 23(1), 253-263.

Jaworski, A., Wikiel, H., \& Wikiel, K. (2013). Automated AC voltammetric sensor for early fault detection and diagnosis in monitoring of electroplating processes. Electroanalysis, 25(1), 278-288.

Macdonald, D. D., Sikora, E., \& Engelhardt, G. (1998). Characterizing electrochemical systems in the frequency domain. Electrochimica Acta, 43, 87-107.

Ming, P. M., Zhu, D., Zeng, Y. B., \& Hu, Y. Y. (2010). Wear resistance of copper EDM tool electrode electroformed from copper sulfate baths and pyrophosphate baths. The International Journal of Advanced Manufacturing Technology, 50(5), 635-641.
Mosallam, A., Medjaher, K., \& Zerhouni, N. (2013). Nonparametric time series modelling for industrial prognostics and health management. The International Journal of Advanced Manufacturing Technology, 69(5), 1685-1699. https://doi.org/10.1007/s00170-0 13-5065-z.

Mosallam, A., Medjaher, K., \& Zerhouni, N. (2016). Data-driven prognostic method based on Bayesian approaches for direct remaining useful life prediction. Journal of Intelligent Manufacturing, 27(5), 1037-1048. https://doi.org/10.1007/s10845-014-0933-4.

Paunovic, M., \& Schlesinger, M. (2006). Fundamentals of electrochemical deposition (2nd ed., pp. 77-112). New York: Wiley.

Piratoba Morales, U., Mariño Camargo, A., \& Olaya, J. J. (2010). Diagramas Típicos Con Circuitos Equivalentes electrochemical impedance-interpretation of typical diagrams with equivalent circuits. Dyna, 77(164), 69-75.

Poon, G. K. K., Williams, D. J., \& Chin, K. S. (2000). Optimising the lithographic patterning effect in an acid copper electroplating process. The International Journal of Advanced Manufacturing Technology, 16(12), 881-888.

Ragab, A., Ouali, M. S., Yacout, S., \& Osman, H. (2016a). Remaining useful life prediction using prognostic methodology based on logical analysis of data and Kaplan-Meier estimation. Journal of Intelligent Manufacturing, 27(5), 943-958.

Ragab, A., Yacout, S., Ouali, M.-S., \& Osman, H. (2016b). Prognostics of multiple failure modes in rotating machinery using a patternbased classifier and cumulative incidence functions. Journal of Intelligent Manufacturing. https://doi.org/10.1007/s10845-016-1 244-8.

Schuldiner, S., \& Rosen, M. (1972). The exchange current density vs. concentration relation and its use in a rigorous determination of solution purity. Journal of Electroanalytical Chemistry and Interfacial Electrochemistry, 35(1), 1-6.

Sikorskaa, J. Z., Hodkiewicz, M., \& Ma, L. (2011). Prognostic modelling options for remaining useful life estimation by industry. Mechanical Systems and Signal Processing, 25(5), 1803-1836.

Takahashi, K. M. (2000). Electroplating copper onto resistive barrier films. Journal of the Electrochemical Society, 147(4), 1414.

Tsai, T.-N. (2014). A hybrid intelligent approach for optimizing the fine-pitch copper wire bonding process with multiple quality characteristics in IC assembly. Journal of Intelligent Manufacturing, 25(1), 117-192.

Vaezi, M., Seitz, H., \& Yang, S. (2013). A review on 3D microadditive manufacturing technologies. The International Journal of Advanced Manufacturing Technology, 67(5), 1721-1754.

Vogl, G. W., Weiss, B. A., \& Helu, M. (2016). A review of diagnostic and prognostic capabilities and best practices for manufacturing. Journal of Intelligent Manufacturing. https://doi.org/10.1007/s10 845-016-1228-8.

Yu, C., Wang, P., Gao, X., \& Wang, H. (2015). A novel mathematical method for equivalent circuit modeling determination for electrochemical impedance spectroscopy to study corrosion behavior of corrosion resistant steel. International Journal of Electrochemical Science, 10(1), 538-551. 